\author{
Professor Margareta FLORESCU, PhD (Corresponding author) \\ Department of Administration and Public Management \\ The Bucharest University of Economic Studies \\ E-mail: margareta.florescu@ari.ase.ro \\ Professor Marian NĂSTASE, PhD \\ Department of Management \\ The Bucharest University of Economic Studies \\ E-mail: nastasem1@yahoo.com \\ Professor Mihai ORZAN, PhD \\ Department of Marketing \\ The Bucharest University of Economic Studies \\ E-mail: mihai.orzan@ase.ro \\ Lecturer Shahrazad HADAD, PhD \\ UNESCO Department for Business Administration \\ The Bucharest University of Economic Studies \\ E-mail: shahrazad.hadad@fabiz.ase.ro
}

\title{
RESEARCH PERFORMANCE PREDICTORS IN ROMANIAN UNIVERSITIES: THE CASE OF THE BUCHAREST UNIVERSITY OF ECONOMIC STUDIES
}

\footnotetext{
Abstract.The paper brings a holistic approach to evaluating performance research in a higher education university able to capture the characteristics of the socio-economic field through a statistical analysis of the various research components, research funding being used as input, and research output as the result of the investigation. Researchers' performance is a key requirement in this changing environment, and this must be an important concern for academic research institutions to obtain competitive funding that provides an interface and stimulate scientific productivity. In this paper, we deliberately concentrate on a multiple regression analysis using the characteristics of the research projects carried out, the value, the impact, as independent variables, depending on the number of scientific articles as a dependent variable. This investigation defines institutional performance research on the basis of an empirical study of extended research indicators that can be practically institutionalized and explicitly reflected in its management.

Keywords: higher education institution; research indicators; scientific articles; conference participation; partial least squares.
}

JEL Classification: A200, A220, A230, I2, Y9 


\section{Introduction}

The holistic approach to the performance of institutional research and its management is a pragmatic necessity of open innovation viewed from the perspective of the intellectual property of the research community within a higher education institution. Therefore, the integration of advanced scientific research at research universities, interdisciplinary research, paradigm shift, the need to evaluate the performance of research have gone through a necessary metamorphosis for the institutional competitive system. Researchers' performance is a key requirement in this changing environment, and this must be an important concern for academic research institutions to obtain competitive funding that provides an interface and stimulate scientific productivity. In this respect, in addition to teaching and education, scientific research and performance is one of the main concerns of an elite university. Universities compete on the basis of their scientific production against each other to attract competitive research funding and student finance from the Government to enable them to support progress and competitiveness (Altbach 2009, Andrei et al. 2016, Ausloos 2015, Bibu et al. 2016, Florescu 2012, Popa et al. 2019).

Under the pressure posed by the emergence of informal education and the claims of the labor market that universities and their activities have become irrelevant, universities have now engaged in new endeavors in order maintain their student and capitalize on their research(Bratianu 2014, Bratianu\&Panzaru 2015, Books 2005, Glaser-Segura et al. 2007). Universities are trying to attract funds for research, students, and material base by means of projects(Glass et al. 1995, Godin \&Gingras 2000, Habib \&Jungthirapanich 2008). Why is research important in their quest? Because research is a highly praised component within the university rankings and it represents a measure of the quality and its internationalization dimension reflected in the ability of the university to attract national/international projects, write scientific articles participate at scientific conferences, etc. Digitalization of research opens new perspectives and on innovation and fosters new behaviors in order to harmonize the internal resources of organizations with the challenges and demands of external environment (Ciocoiu et al. 2011, Florescu 2012). Universities and other higher education institutions are hailed as being the engines of social and economic progress, and they are reckoned among the central institutions of knowledge economies (Bratianu\&Panzaru 2015, Godin \&Gingras 2000).

The debate on whether the quality of university research should be assessed based on peer review or quantitative metrics still continues with the adjacent pros and cons (Glass et al. 1995, Taylor 2011). Measuring the research dimension of a university can prove to be useful for different purposes: institution assessment, audit, staff promotion, budget allocation (Amara et al. 2015, Kiely et al. 2019, Lahaye et al. 2012, Marinescu\& Valimareanu 2018, Teodorescu\& Andrei 2011). 
Research Performance Predictors in Romanian Universities: The Case of the Bucharest University of Economic Studies

The research component is divided into multiple sub-components such as: number of researchers, number of research institutes that a university has, number of research laboratories, number of journal articles published, number of conference papers, number of doctoral school, number of Ph.D. students, number of professors who are Ph.D. coordinators, number of Nobel prize laureates, number of research projects conducted, number and value of research grants, patents, and the list may continue(Herteliu et al. 2017, Miskiewicz 2013, Zhou et al. 2012).

From these, we decided to focus on projects as input and having as output the scientific production reflected by the journal articles published and conference papers. Section 2 introduces the research model and the set of plausible hypothesis we have started with. Section 3 casts light over the methodology employed and the statistical analyses performed, while Section 4 presents the numerical results. Section 5 concludes the paper and reflects on the implications of the research.

\section{Research model and hypotheses}

The analysis adds value in the field of research-development-innovation evaluation in a holistic vision including research projects carried out in the university and correlating indicators for project performance. At the same time it shows how "actors" involved in the process of capitalizing on scientific, the researchers, had efficient and effective scientific productivity while identifying the synergies and tensions between the various factors under consideration, with the possibility of taking over, adapting and refining the good practices in the field of the evaluation of the academic scientific research.

In order to predict the research results (journal articles and conference papers) within The Bucharest University of Economic Studies, we proposed the following model:

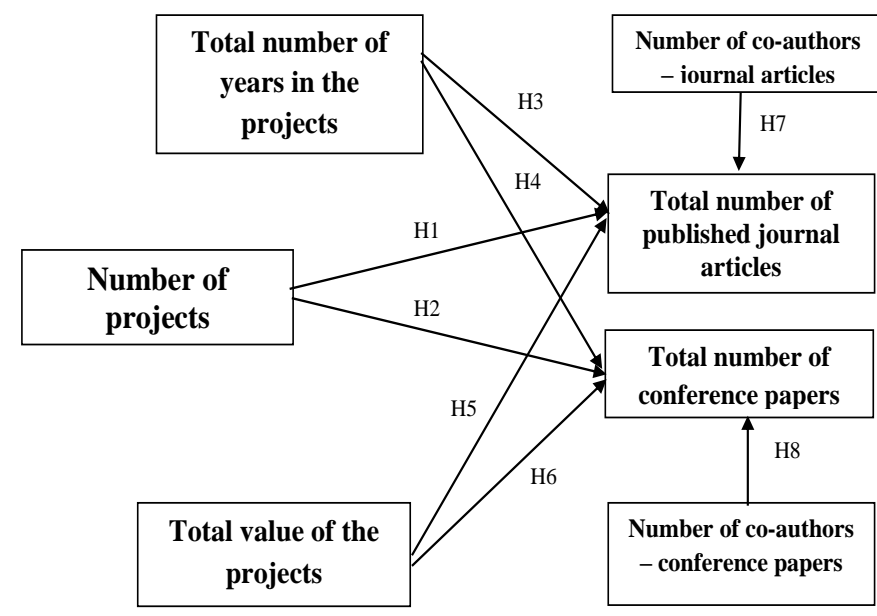

Figure1. Research model: Research result predictors among professors 
The main predicting factors that have been analyzed with respect to research performance within The Bucharest University of Economic Studies, measured by the total number of journal published articles by each professor and the total number of conference papers represent the total number in which the respective professor has been involved, the total number of years she was involved in the project and the total value of the project.

We posit that these three predictors influence the number of journal articles published and the number of conference papers, because, within the projects, regardless of their financing source, as long as they have a research component, they will have objectives, activities and results translated into deliverables that have to be achieved within strict time frames. The higher the financing of the project, the higher the budget allocated to research activity, and as such, the higher the number of journal articles published and conference papers.

Therefore we make the assumption that the three predictors objectified by the indicators for measuring the involvement in projects and their respective financing influence the research results, the number of published journal articles and the number of conference papers, leading to the following hypotheses:

Hypothesis 1:The number of projects in which a professor is involved has a direct and positive influence over the number of journal articles.

Hypothesis 2:The number of projects in which the professor is involved has a direct and positive influence over the number of conference papers.

Hypothesis 3:The total number of years in which the professor was involved in the project has a direct and positive influence over the number of journal articles.

Hypothesis 4:The total number of years in which the professor was involved in the project has a direct and positive influence over the number of conference papers.

Hypothesis 5:The total value of the projects in which the professor is involved has a direct and positive influence over the number of journal articles.

Hypothesis 6:The total value of the projects in which the professor is involved has a direct and positive influence over the number of conference papers.

Besides the predictors that relate to the involvement degree of the project of the professors, other important predictors are the degree of cooperation among authors (co-authorships), making the assumption that teamwork has a direct and positive influence over their research performance, due to obvious reasons such as facilitating writing scientific papers by splitting the tasks according to the team members' specialization, high motivation and need to comply with the deadline. Consequently, we develop the following assumptions:

Hypothesis 7:The number of journal article co-authorships belonging to a professor has a direct and positive influence over the number of journal articles. 
Research Performance Predictors in Romanian Universities: The Case of the Bucharest University of Economic Studies

Hypothesis 8:The number of conference paper co-authorships belonging to a professor has a direct and positive influence over the number of conference papers.

\section{Methodology}

The analyzed database comprises 437 entries containing information about journal articles, conference papers and projects in which the professors of The Bucharest University of Economic Studies were involved, during 2007-2018. The initial database contained 2000 entries, however out of these 2000 only 437 were complete in order to become the subject of this analysis. The data objectively present reality, they are not estimations, or averages or other statistical indicators. The EXCEL database has been imported into the statistical analysis packageIBM SPSS Statistics (George \&Mallery 2013), and further analyzed by means of structural equation modelling using WarpPLS6.0 (Kock 2017).

All the observed variables of the model, independent or dependent, are depicted in the following table, together with their correlations.

Table 1 - Correlations among the variables of the model

\begin{tabular}{|l|c|c|c|c|c|c|c|}
\hline & CoopArt & NoArt & NoConf & CoopConf & NoProj & YeProj & ValProj \\
\hline CoopArt & $\mathbf{1 . 0 0 0}$ & 0.848 & 0.354 & 0.304 & 0.334 & 0.227 & 0.188 \\
\hline NoArt & 0.848 & $\mathbf{1 . 0 0 0}$ & 0.407 & 0.329 & 0.408 & 0.319 & 0.256 \\
\hline NoConf & 0.354 & 0.407 & $\mathbf{1 . 0 0 0}$ & 0.793 & 0.446 & 0.475 & 0.397 \\
\hline CoopConf & 0.304 & 0.329 & 0.793 & $\mathbf{1 . 0 0 0}$ & 0.434 & 0.451 & 0.430 \\
\hline NoProj & 0.334 & 0.408 & 0.446 & 0.434 & $\mathbf{1 . 0 0 0}$ & 0.726 & 0.516 \\
\hline YeProj & 0.227 & 0.319 & 0.475 & 0.451 & 0.726 & $\mathbf{1 . 0 0 0}$ & 0.651 \\
\hline ValProj & 0.188 & 0.256 & 0.397 & 0.430 & 0.516 & 0.651 & $\mathbf{1 . 0 0 0}$ \\
\hline
\end{tabular}

*All probabilities associated to the above correlation coefficients are smaller than 0.001

As one can notice, the Pearson correlation coefficients exhibit values that are uniformly distributed within the positive range [0, 1], namely: low (less than 0.3 ), medium (between 0.3 and 0.7), and strong correlation (higher than 0.7). Noteworthy is the strong correlation between the number of published journal articles and the number of co-authorships with respect to journal papers, 0.848 , and the correlation between the number of conference papers and the number of coauthorships with respect to conference papers, 0.793 , indicating that cooperation and teamwork have a strong influence over the research results.

A simple mathematical depiction of the (linear) multiple regression model is provided in the following equation (Agapie et al. 2018).

$$
Y_{i}=\beta_{0 i}+\beta_{1 i} X_{1}+\beta_{2 i} X_{2}+\beta_{3 i} X_{3}+\beta_{4 i} X_{4 i}+\varepsilon_{i} \quad i=1,2
$$

Notice that $Y_{i}$ stand for the two dependent (predicted) variables, namely NoArt (for index $\mathrm{i}=1$ ) and NoConf (for $\mathrm{i}=2$ ). The first coefficient, $\beta_{0 i}$, stands for a constant parameter. Parameters $\beta_{1 i}, \beta_{2 i}$ and $\beta_{3 i}$ are the coefficients associated to the 


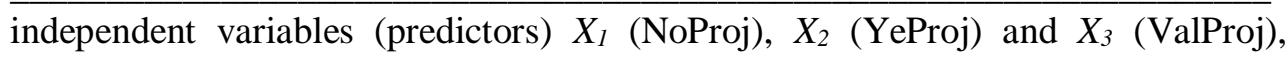
respectively. Parameter $\beta_{4 i}$ is the coefficient corresponding to the independent variables $X_{4 i}$ (CoopArt for $\mathrm{i}=1$, respectively CoopConf for $\mathrm{i}=2$ ). Lastly, $\varepsilon_{i}$ defines the residual error of our estimated models by accounting for the unexplained variation in $Y_{i}$, in each of the two equations (1).

Additionally, the Partial Least Squares (PLS) method applied by WarpPLSinvolves also a factor analysis (principal component) technique like the one employed in (Vizitiu et al. 2018). PLS was initially devoted as an econometric instrument (Wold 1966) and became very popular in both social sciences and chemistry (Herve 2010,Pages \&Tennenhaus 2001).

PLS works as follows. We start with a matrix $M_{Y}$ of size $437 \times 2$, whose entries are the values of the two dependent variables $Y_{i}$, recorded for each of the 437 observations. Similarly, the values of the five independent variables $X_{i}$ for each of the 437 observations are collected in a matrix $M_{X}$, of size $437 \times 5$. We aim to describe the relationship between the two matrices, and finally to predict $M_{Y}$ from $M_{X}$. According to (Herve 2010), if $M_{X}$ is full rank an ordinary multiple regression would achieve the goal; but the technique is no more tractable when the size of $M_{X}$ is considerably large, due to a high risk of multi-collinearity. That is the typical case for PLS, which looks for a set of factors from a simultaneous decomposition of $M_{X}$ and $M_{Y}$, factors that explain as much as possible of the covariance between the two matrices. A regression step like the one depicted in Eq. (1) follows the decomposition, with the factors predicting the dependent variables.

The factors, or the independent variables analyzed inWarpPLS each contain a single item (observed variable). We chose WarpPLS for the multivariate statistical analysis, although the variables are mono-item, because we have two chains of multiple regression with two dependent variables and five independent ones, requiring therefore a structural/simultaneous equation analysis. WarpPLS is specially built for such analyses leading to very good estimates of causal relations that cannot be represented by linear equations, but by resorting to non-linear relations.

\section{Results and discussions}

The proposed research model was analyzed and estimated by resorting to WarpPLS 6.0, using the Bootstrap sampling method(Tabachnick\&Fidell 2007). WarpPLS is able to analyze non-linear relations between the independent variables of the model, and also relations of type $\mathrm{U}$ or $\mathrm{S}$, using the method of variance(Kock 2017). Additionally, this software offers conformity and quality indicators with respect to the proposed model.

Figure 2 displays the $\beta$-coefficients of the model and their associated probabilities, and also the $\mathrm{R}^{2}$ coefficients. The results show that the variation of the dependent variable NoArt (number of journal articles published by a professor during 2007-2018) is explained to a large degree, 74\%, by its predictors, respectively: CoopArt(number of cooperations for journal articles) with a $\beta$ coefficient of 0.8 , NoProj (number of projects the professor was involved in) with 
Research Performance Predictors in Romanian Universities: The Case of the Bucharest University of Economic Studies

a $\beta$-coefficient of 0.09 , YeProj (number of years the professor was involved in the project) with a $\beta$-coefficient 0.06 , and ValProj (total value of projects in which the professor was involved) with a $\beta$-coefficient of 0.02. Therefore, Hypotheses $1,3,5$ and 7are confirmed.

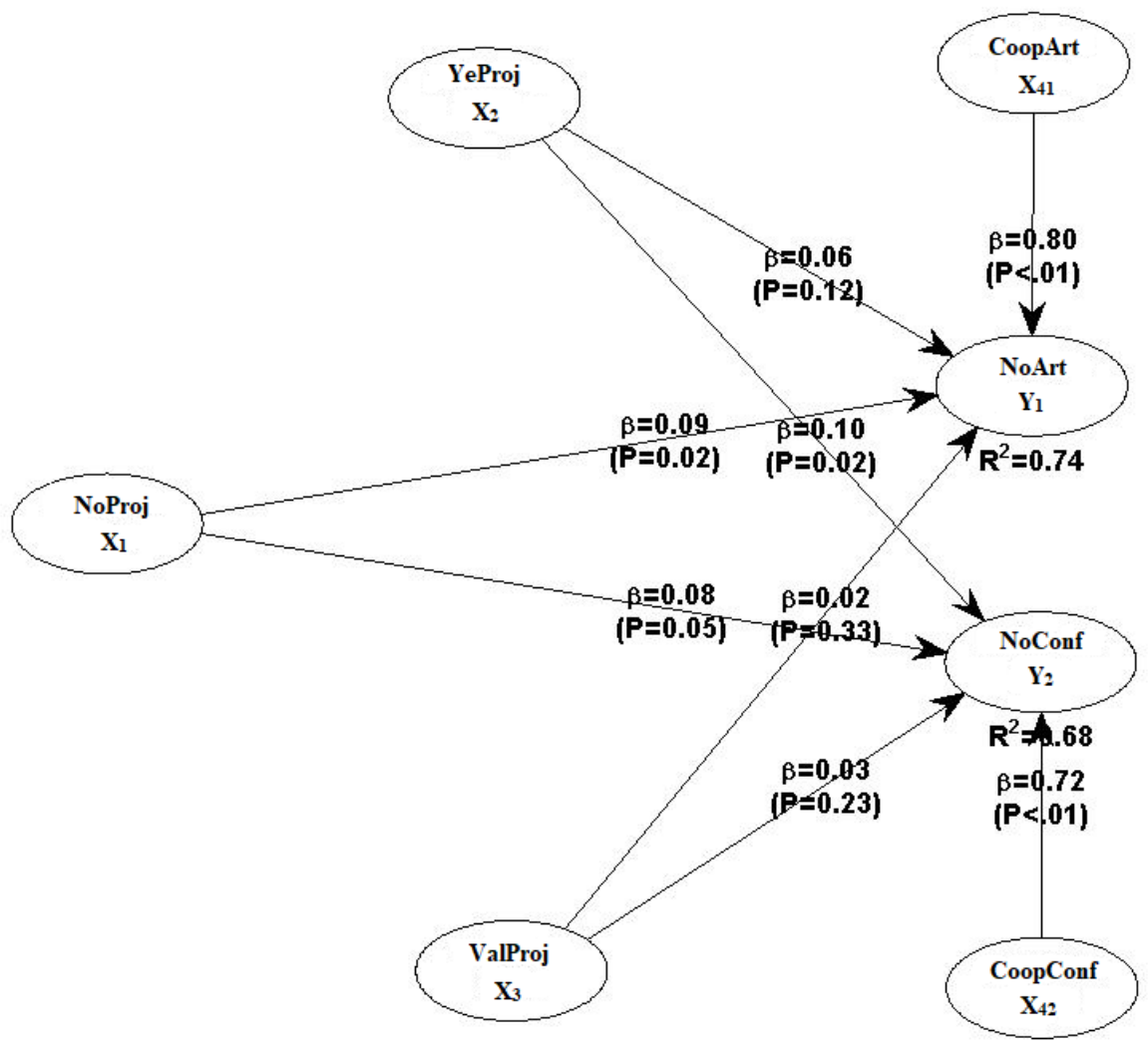

Figure 2. Estimated model using WarpPLS 6.0 analysis

In what regards the dependent variable NoConf (number of conference paper of a professor), its variation is explained to a large extent, 68\%, by the variance of the independent variables. The strongest influence is exhibited by CoopConf (number of cooperations in terms of conference papers) with a $\beta$ coefficient of 0.68 , followed by YeProj with a $\beta$-coefficient of 0.1 , NoProjwith a $\beta$ coefficient of 0.08 , andValProj with a $\beta$-coefficient of 0.03.ThusHypotheses2, 4, 6 and 8 are confirmed as well.

In order to validate the model, it is mandatory to analyze the quality and conformity indicators estimated through WarpPLS 6.0. The ten indicators are presented in Table 2. 
Table 2 - Conformity and quality indicators of the model estimated with WarpPLS 6.0

\begin{tabular}{|c|c|}
\hline Indicator & Criterion \\
\hline Average path coefficient $(\mathrm{APC})=0.238$, & $\mathrm{P}<0.001$ \\
\hline Average R-squared $(\mathrm{ARS})=0.712$ & $\mathrm{P}<0.001$ \\
\hline Average adjusted R-squared (AARS) $=0.710$, & $\mathrm{P}<0.001$ \\
\hline Average block VIF $(\mathrm{AVIF})=2.377$ & acceptable $<=5$, ideal $<=3.3$ \\
\hline Average full collinearity VIF (AFVIF)=2.903, & acceptable $<=5$, ideal $<=3.3$ \\
\hline TenenhausGoF $(\mathrm{GoF})=0.844$ & low $>=0.1$ \\
\hline & medium $>=0.25$ \\
\hline Sympson's paradox ratio $(\mathrm{SPR})=1.000$, & acceptable $>=0.7$, ideal $=1$ \\
\hline R-squared contribution ratio (RSCR) $=1.000$, & acceptable $>=0.9$, ideal $=1$ \\
\hline Statistical suppression ratio $(\mathrm{SSR})=1.000$ & acceptable $>=0.7$ \\
\hline $\begin{array}{l}\text { Nonlinear bivariate causality direction ratio } \\
\text { (NLBCDR }=1.000 \text {. }\end{array}$ & acceptable $>=0.7$ \\
\hline
\end{tabular}

All the ten indicators in the table have excellent values. AVIF, which is the most important measure of the conformity of the model is 2.377 which is ideal being under the 3.3 margin; whereas ARS is 0.712 for a probability lower than 0.001 . Also, APC is another important indicator and its value is 0.238 for a probability lower than 0.001 .

\section{Conclusions}

In this study, the empirical analysis of the performance of institutional scientific research explicitly included correlations between important research indicators within a Romanian higher education institution by placing a university professor / researcher at the centrum for a statistical analysis initially designed.The particularity of our study is that we look at the professor from two different perspectives, as both the beneficiary of research funding via grants and research projects, and also as the author of scientific production such as journal articles and conference papers. We have formulated some plausible statistical hypotheses in order to reveal the hidden connections between scientific production and research funding, and we have tested these hypotheses by means of multiple regression analysis.

An important finding of our statistical analysis is that the number of coauthors has the highest influence onto the scientific production of university professors, when it comes to both output indicators, journal articles and conference papers. This is somehow expected, since over the last decades economic Romanian universities indulged large collaborative authorships as a general rule.

We found out that not all the variables that characterize a research project have necessary a significant influence onto the production of articles. Thus, the 
Research Performance Predictors in Romanian Universities: The Case of the Bucharest University of Economic Studies

total value of projects a professor is involved in does produce an increment of her scientific production, with respect to journal articles and to conference papers, but not to the extension that someone would expect. In practice, there is a diversity in the scientific production that is normally connected to the specificity of projects. Some projects are not necessary research oriented, but they are more pragmatic, targeting the development of some competencies of different sort.The duration of the projects (expressed as total number of years the projects receive funding) has also some positive influence on the number of conference papers, yet again no significant influence on the production of journal articles. It is also directed linked to the projects specificity, to the particular requirements associated to that call or to the funding program. These findings could be explained by the fact that research money stimulate scientific cooperation, yet the production of peer reviewed, Web of Science journal articles is a more in-depth creative process, time consuming and requires for top quality scientific production a continuous effortrelated to direct funding, but also to creating a stimulating environment for researchers, both at national and international levels. We feel that these conclusions should be further investigated for validation in either national or international academia.

On the other hand, a limitation of the present study refers to some recent adjustments to the national promotion criteria in economic academia. Since 2017, the number of co-authors working in universities/research institutions from abroad is not taken into account any more in the formula that calculates the total journal article authorship index of the candidate. Normally, such modification would have the effect of fostering international cooperation with respect to the production of research articles, which would be worth analyzing quantitatively. Yet, provided the relatively short time since the introduction of the new formula, the statistical analysis of the corresponding effects is deferred to a future study.

Academic performance of advanced research and the development of a management system are essential for leadership efficiency and efficiency in today's universities. In the future, a detailed understanding of the impact of specific norms or objectives on academic organizations, along with pilot studies will attempt to establish a generalized and scalable framework as a steering system for academic projects, will be a higher priority. 
Margareta Florescu, Marian Năstase, Mihai Orzan, Shahrazad Hadad

\section{ACKNOWLEDGEMENTS}

The authors acknowledge support from the project CNFIS-FDI-2018-0582

entitled "Supporting excellent research within the Academy of Economic Studies in Bucharest in the context of the principles of sustainable development and open research" (ORFEUS).

The last author acknowledges the support provided by The Bucharest University of Economic Studies (ASE) „Dezvoltarea abilitatilor antreprenoriale pentru doctoranzi si postdoctoranzi în domeniul stiinţelor economice” POCU/380/6/13/125015.

\section{REFERENCES}

[1] Agapie, A., Vizitiu, C., Cristache, S., Năstase, M., Crăciun, L., Molănescu, A.(2018), Analysis of Corporate Entrepreneurship in Public R\&D Institutions. Sustainability, 10(7), 2297;

[2]Altbach, P. G. (2009),Peripheries and Centers: Research Universities in Developing Countries. Asia Pacific Education Review, 10(1), 15-27;

[3] Amara, N., Landry, R., Halilem, N.(2015), What Can University Administrators Do to Increase the Publication and Citation Scores of their Faculty Members? Scientometrics, 103(2), 489-530;

[4]Andrei, T., Teodorescu, D., Mirică, A.(2016),Beyond the Impact Factor: Measuring the International Visibility of Romanian Social Sciences Journals. Scientometrics, 108(1), 1-20;

[5]Ausloos, M.(2015),Coherent Measures of the Impact of Co-Authors in Peer Review Journals and in Proceedings Publications. Physica A: Statistical Mechanics and its Applications, 438, 568-578;

[6]Bibu, N.A. Sala, D.C., Alb, M.(2016), Specific and Common Features in Fast-growing Companies from the Timis County (Romania). 2016/6/7, ProcediaSocial and Behavioral Sciences, 221, 49-56, Elsevier;

[7]Bratianu, C.(2014),Intellectual Capital of the European Universities. In Handbook of research on trends in European higher education convergence, 24-43, IGI Global;

[8]Bratianu, C., Pinzaru, F.(2015),Challenges for the University Intellectual Capital in the Knowledge Economy. Management Dynamics in the Knowledge Economy, 3(4), 609;

[9]Brooks, R.(2005), Measuring University Quality. The Review of Higher Education, 29(1), 1-2, Johns Hopkins University Press. Retrieved February 13, 2019, from Project MUSE database;

[10]Ciocoiu, N.,Dobrea, C.,Tartiu, V.(2011), The Role of Consumer Behaviour in E-Waste Management System in Romania. Revista de Management Comparat International/Review of International Comparative Management, Faculty of Management, The Bucharest University of Economic Studies, Bucharest, Romania, 12(6), 208-214; 
Research Performance Predictors in Romanian Universities: The Case of the Bucharest University of Economic Studies

[11]FlorescuM.S.(2012),Management of Publicly Financed Projects-A Practical Approach. Economica Publishing;

[12]George, D.,Mallery, P.(2013),SPSS for Windows Step by Step: A Simple

Guide and Reference; Allyn \& Bacon: Boston, MA, USA;

[13]Glaser, Segura, D. A., Mudge, S., Brătianu, C., Jianu, I., Valcea, S. (2007), Quality Improvement of Business Education in Romanian Universities: The Student as Customer and Client. Higher Education in Europe, 32(2-3), 121-133; [14]Glass, J. C., McKillop, D. G., Hyndman, N.(1995),Efficiency in the Provision of University Teaching and Research: An Empirical Analysis of UK Universities. Journal of applied Econometrics, 10(1), 61-72;

[15]Godin, B., Gingras, Y. (2000),The Place of Universities in the System of Knowledge Production. Research policy, 29(2), 273-278;

[16]Habib, M., Jungthirapanich, C.(2008),An Integrated Framework for

Research and Education Supply Chain for the Universities. In IEEE International Conference on Management of Innovation and Technology, 1027-1032;

[17]Herteliu, C., Ausloos, M., Ileanu, B. V., Rotundo, G., Andrei, T.(2017), Quantitative and Qualitative Analysis of Editor Behavior through Potentially Coercive Citations. Publications, 5(2), 15;

[18]Herve, A.(2010),Partial Least Squares Regression and Projection on Latent Structure Regression (PLS Regression). WIREs Comp Stat, 2: 97-106. doi: 10.1002/wics.51;

[19]Kiely, K., Brennan, N., Hayes, A.(2019),Measuring Research in the University via Senior Academic Promotions and Faculty Research Metrics. Procedia Computer Science, 146, 173-181;

[20]Kock, N.(2017), WarpPLS User Manual: Version 6.0.Laredo, TX: Script Warp Systems;

[21]Lahaye, L., Cristache, N., Dal Fior, C., Capatina, A., Maloteau, P. (2012), CSR Initiatives in two Higher Education Institutions from Belgium and Romania. Risk in Contemporary Economy, 213-218;

[22]Marinescu, C., Valimareanu (Mircioi), I. (2018), Methodological and Theoretical Considerations Regarding Informality on the Labor Market. Review of International Comparative Management, 19(1), 54-64;

[23]Miśkiewicz, J.(2013),Effects of Publications in Proceedings on the Measure of the Core Size of Coauthors. Physica A: Statistical Mechanics and its Applications, 392(20), 5119-5131;

[24]Pages, J., Tenenhaus, M.(2001),Multiple Factor Analysis Combined with Plspath Modeling. Application to the Analysis of Relationships between PhysicOchemical Variables, Sensory Profiles and Hedonic Judgments. Chemometrics and Intelligent Laboratory Systems, 58, 261-273;

[25]Popa, A., Hadad, S., Paiusan, R., Nastase, M.(2019), A New Method for Agricultural Market Share Assessment. Sustainability, 11(1), 88;

[26]Tabachnick, B.G.,Fidell, L.S.(2007),Using Multivariate Statistics, Pearson: Boston, MA, USA; 
Margareta Florescu, Marian Năstase, Mihai Orzan, Shahrazad Hadad

[27]Taylor, J.(2011),The Assessment of Research Quality in UK Universities:

Peer Review or Metrics? British Journal of Management, 22(2), 202-217;

[28]Teodorescu, D., Andrei, T. (2011), The Growth of International

Collaboration in East European Scholarly Communities: A Bibliometric

Analysis of Journal Articles Published between 1989 and 2009.

Scientometrics,89(2), 711-722;

[29]Vizitiu, C., Agapie, A., Paiusan, R.,Hadad, S.,Nastase, M.(2018),Adapting

Corporate Entrepreneurship Assessment Instrument for Romania. S. Afr. J. Bus. Manag., 49, 1-7;

[30]Wold, H.(1966),Estimation of Principal Components and Related Models by Iterative Least Squares. In P.R. Krishnaiaah (Ed.). Multivariate Analysis, 391420, New York: Academic Press;

[31]Zhou, Y. B., Lï, L., Li, M.(2012),Quantifying the Influence of Scientists and their Publications: Distinguishing between Prestige and Popularity. New Journal of Physics, 14(3), 033033. 